\title{
Representación social y formas de aproximación didácticas y éticas al cine por maestros: una exploración con palabras, creencias, estrategias e imágenes
}

\author{
Rafael Tonatiuh Ramirez Beltrán* \\ Universidad Anáhuac México Norte
}

El presente reporte de investigación es un estudio exploratorio con metodología cualitativa, en el que los sujetos de estudio fueron maestros de educación superior. Tiene como objetivo encontrar datos significativos para la elaboración de una estrategia que posibilite trabajar principios y valores en el salón de clase desde una propuesta innovadora de ver el cine.

La investigación se realizó en abril del 2008, en el marco de la elaboración de un Manual de cine y educación. Trabaja sobre las opiniones y creencias de los informantes en partes conceptuales, de conocimientos y saberes de los profesores sobre la ética, la educación, el cine y las estrategias didácticas.

Palabras clave: Representación social, cine y ética, cine y educación.

The present research report is an exploratory study with qualitative methodology, in which the subjects of study were teachers of university level. Its objective is to find significant data for the elaboration of a strategy that makes it possible to work principles and values in the classroom from an innovative proposal of watching movies.

* Es Sociólogo, Maestro en Ciencias y Candidato a Doctor en Administración. Profesor en la Escuela de Comunicación de la Universidad Anáhuac México Norte. Investigador adscrito al Centro de Investigación para la Comunicación Aplicada (CICA), Escuela de Comunicación, Universidad Anáhuac. Pertenece a Nerea (Asociación Internacional de Investigadores en Educación Ambiental.). Tiene como líneas de investigación los imaginarios y representación en torno al cine y la educación, la comunicación y educación ambiental. Correo electrónico: rramirez@anahuac.mx 
The research was done out in April of 2008, within the development of an Education Movies Manual. It works on the opinions and beliefs of the informants in conceptual parts, of the professors' knowledge of ethics, education, movies and the didactic strategies.

Key words: Social representation, cinema and ethics, cinema and education.

\section{INTRODUCCIÓN}

Teniendo como referente la línea de investigación cine y educación, en el eje de los usos didácticos del cine, se realizó la presente investigación cualitativa con maestros universitarios sobre su conocimiento, función que le atribuyen, las relación que establecen, los usos pedagógicos que le asignan y la articulación del cine con la ética.

La indagación en este caso particular se concreta en la aproximación ética desde películas recientes, realizadas en el siglo xxi. Nuestro interés es realizar una propuesta estratégica para que los maestros y alumnos utilicen el cine en el salón de clase en forma pensada, crítica, activa, con toma de decisiones fundada y participativa. Romper con la pasividad e impunidad que propician los medios, proponiendo una nueva forma de verlos y aprovecharlos. Por eso era indispensable partir de las representaciones y usos que tiene los maestros.

En el documento de propuesta Manual de cine y ética se incluirá un apartado teórico amplio sobre el cine, la ética y la educación, del cual sólo está un resumen en esta versión, por cuestión de espacio.

Explicitamos el problema central de la investigación: ¿¿Se pueden proponer algunas estrategias, actividades y recursos didácticos y éticos para una recepción más profunda, activa y crítica de los contenidos cinematográficos del siglo xxı?

Lo que continuación se presenta es una muestra de lo que el trabajo de campo con maestros puede generar. Profesores que son los protagonistas del hecho educativo y que con demasiada frecuencia no son tomados en cuenta en las decisiones escolares. Sus palabras hablarán por ellos.

\section{El INSTRUMENTO}

La indagación se realizó por medio de un instrumento elaborado ex profeso para dar sustento y horizonte a un documento mayor sobre estrategias educativas 
de uso del cine. Consta de 10 preguntas centrales y otras subordinadas. Los cuestionamientos están enfocados en el cine (películas, usos, impacto, valor educativo) y la ética (concepto personal, formas de aproximación didácticas), así como la relación entre la educación que promueve valores y el cine. Tiene una primera parte de información general sobre el entrevistado y dos preguntas que insisten en la vinculación de películas, valores y secuencias; en la primera se les pide que hagan una lista de películas y los valores que promueven. En la segunda parte se les propuso las películas recientes con las que se pensaba trabajar.

\section{El ObJeTIVO EXPLíCito DE LA INVESTIGACIÓN}

El propósito de esta indagación es recolectar y analizar información entre maestros de educación superior sobre la aplicabilidad didáctica del cine en el salón de clase, en particular nos interesa destacar la representación, percepción y opiniones de maestros en relación a cómo con los filmes de la primera década siglo Xxi, de diferentes partes del mundo, pueden trabajarse con valores humanos y hacerlos significativos entre los alumnos, de diferentes niveles del sistema educativo nacional en particular los de la educación superior.

\section{UBICACIÓN}

El tipo de exploración es una investigación de aproximación cualitativa, por tanto busca la subjetividad de las personas, lucha por encontrar su interioridad pensante y el valor de lo dicho por ellas en una resignificación interpretativa. Lo que pretendemos es encontrar sentido en opiniones y juicios de maestros con gusto por el cine y una vinculación con elementos de la ética, más que el dicho de expertos. Por lo anterior, la técnica cualitativa es híbrida, está a medio camino entre la entrevista con cierto nivel de profundidad, el método Delphi (en el caso, expertos en educación) y el cuestionario no cuantificable. Nos interesaba confrontar nuestras dudas con las creencias y certidumbres de gente próxima al tema, sobre todo con la parte interna, creativa, conceptual, pedagógica y, del mismo modo de experiencia real en el aula.

Nos incentivó en esta exploración, sobre todo, destacar información y verbalizaciones de profesionales cercanos a la trinchera escolar para que enriquecieran el proyecto en que estamos, encontrando luces que iluminarán el uso ético del cine en el salón de clase.

Representación social y formas de aproximación didácticas $\bullet 26 \mathrm{I}$ $y$ éticas al cine por maestros: una exploración con palabras, creencias, estrategias e imágenes 


\section{LOS INFORMANTES}

Buscamos que los informantes tuvieran tres elementos en común:

- Que ejercieran o hubieran ejercido el magisterio en alguna parte del sistema educativo nacional, principalmente en nivel universitario, por lo menos un tiempo.

- Cultura general sobre todo en aspectos científicos, humanísticos y éticos.

- Gusto y cierto manejo didáctico del arte cinematográfico.

Como referencia; la escolaridad de los participantes es: $60 \%$ de licenciatura, $30 \%$ de maestría y $10 \%$ de doctorado. En cuanto al género, $80 \%$ son hombres y $20 \%$ mujeres.

\section{Algunos antecedentes y elementos teóRicos}

Como se explicitó, esta investigación se soporta en unos antecedentes, referentes y un trabajo teórico previo, por lo que con el fin de fijar una postura señalamos algunos elementos:

En relación a los antecedentes podemos compartir que junto con un grupo de investigadores desde hace más de dos lustros nos hemos dado a la tarea de documentar los referentes educativos en el arte cinematográfico. Esta experiencia ha generado varios artículos, revistas monográficas, ensayos, investigaciones, ponencias, conferencias y tres libros (La vida es mejor que la Escuela, 1999; Maestra vida, 2000 y Globalización, Cine y Educación, 2003). Entre nuestros hallazgos, hemos encontrado que existe por lo menos una triple relación entre el cine y la educación, a saber:

1. Una relación cinematográfica: experiencias educativas que el docente y los alumnos viven y se recrean en la práctica educativa manifiesta en el arte cinematográfico.

2. Una relación comunicativa: el docente y el alumno como espectador del cine.

3. Una relación pedagógica: el uso didáctico del cine en el salón de clases.

De estas tres problemáticas relaciones hemos desprendido las implicaciones de nuestro campo de análisis que observan al cine, en primer lugar, como una manifestación y proyección de lo educativo, a lo que nombramos lo imaginario del cine en la educación. El segundo objeto de este campo es el que tiene que ver con cómo el cine retrata/documenta/exhibe/crea/recrea el hecho educativo; el cine está condicionado en algunos rasgos por lo educativo, pero también 
condiciona lo educativo. Esto lo conocemos como el imaginario de la educación en el cine. El tercero -y para los fines del presente estudio fundamental, es el uso con fines de aprendizaje que tiene el cine en la práctica educativa, lo que nombramos en tanto concreción pedagógica, el imaginario didáctico del cine.

Del imaginario didáctico del cine hemos encontrado otras investigaciones próximas en Iberoamérica como la impulsada por el Ministerio de Educación de Argentina con el proyecto Cine y Educación en el que realizan cine-fichas. También encontramos sitios en internet en España como el de cine y educación de Enrique Martínez Salanova (www.uhu.es/cine.educacion/cineyeducacion) en el que propone que en el salón de clases se trabajen temas como cine y migración; cine y discapacidad; cine y medio ambiente, etc., además de muchas estrategias didácticas. En nuestro país, la Secretaría de Educación Pública está proponiendo cursos que usan al cine como la herramienta básica para la formación docente como el del "Adolescente y su contexto actual". Otro ejemplo próximo a nuestro objeto de estudio es el de José Uroz y su interesante compilación de historia y cine. También esta el trabajo del Instituto Pedagógico "Padres y Maestros" de Bilbao, España, del libro Cine y transversales, que propone trabajar los temas emergentes o transversales con películas.

En la presente investigación decidimos trabajar desde la representación social como recurso metodológico, por lo tanto, la exploración va hacia elementos como: percepción, simbólica, cognitiva, de interpretación de significantes e ideológica de los maestros en relación al cine y los valores. Ir hacia la representación es ir hacia la médula ideológica de los sujetos. Según Camareno (2002) la relación entre representación social e ideología es estrecha:

La ideología está ligada básicamente a la representación como sistema de representaciones (imágenes, mitos, ideas o conceptos). Crea hábitos, normas de comportamiento, mentalidades, formas de vida, en definitiva imágenes. La ideología es un inconsciente vital que se segrega desde unas relaciones sociales, y que sirve para legitimarlas, convertirlas en lo "natural" y hacer funcionar así a esas relaciones sociales, configurando la individuación de cada vida subjetiva.

En relación a la ética, Attali (2007) prospecta que será, en este siglo xxi, el principal aglutinante social. La ética es una apuesta a la vida, a la centralidad y dignidad de la persona y a la toma de decisiones (Lepe, 2007; Agejas, 2007 y Dusel, 2000). La ética es un campo de conocimiento: científico, racional, práctico, normativo y centrado en los actos humanos (Gutiérrez, 1981; Savater 1991 y 1997). La ética tiene como esencia el significado de la existencia humana (Fromm, 1947).

Representación social y formas de aproximación didácticas $\bullet_{2} 6_{3}$

$y$ éticas al cine por maestros:

una exploración con palabras, creencias, estrategias e imágenes 


\section{LA EJECUCIÓN}

La corrida del instrumento se realizó del 24 de marzo al 4 de abril de 2008, por medio del correo electrónico. Sólo se realizó una vuelta dado que su fin era exploratorio. Nos reservamos el derecho de profundizar en una investigación de más largo aliento (ampliación de informantes y segunda vuelta para profundizar en coincidencias o discrepancias, cruce de resultados con otras metodologías, etc.). Ahora sólo compartimos los datos de este primer tramo del recorrido.

\section{LOS RESULTADOS: EL TRABAJO CON LO EXPRESADO Y LO PENSADO}

\section{Concepto de ética en la muestra}

Nuestro primer interés fue saber qué pensaban nuestros consultados sobre el concepto de ética. La pregunta explícita fue: Defina de manera personal que es la ética. Les solicitábamos en forma clara y directa que no recurrieran a otra fuente que no fueran ellos mismos; al fondo mental o la creencia con que asumen esa palabra. Nos interesaba sobre todo la visión particular con la que asocian el término.

En las verbalizaciones encontramos tres grandes categorías que integraban las ideas básicas subyacentes en el grupo, a saber: la ética y la vida; la ética y la toma de decisiones; y la ética como conjunto de normas. Señalamos la categoría y algún fraseo que ejemplifica lo que queremos mostrar.

a) Relacionar la ética con la vida: la actuación, las acciones y la conducta (inf: 2, 3, 4, 8, y 9):

La ética es el conjunto de normas que rigen la existencia de una comunidad gracias a la cual podemos saber si actuamos correctamente (conforme a la ética) o incorrectamente (contra lo que la ética dicta). (inf. 4)

Es el bien obrar con base en valores humanos. (inf. 9)

b) La ética y la relación con la toma de decisiones: impacto de las misma, repercusión y fondo (inf. $1,6,10$.):

La decisión para el bien hacer. (inf. 1)

Para mí, la ética es la forma en que convivo con el entorno en que me encuentro y en el que mis actos y decisiones tienen impactos diversos. (inf. 6)

La ética es un valor que impulsa al ser humano a tomar las decisiones adecuadas respecto a sus valores y al bienestar de los demás. (inf. 1) 
c) La ética relacionada con valores: principios, normas, el bien y el mal. (inf. 3, 4, 7):

Una actitud y conducta dirigida a defender y promover los valores morales. (inf. 3)

Son los principios y normas morales que nos establecemos y que califican nuestras acciones como personas sin determinarlas malas o buenas. (inf. 7)

Nos parece que estas tres categorías resumen en mucho la trayectoria teórica de la ética que manifiestan autores contemporáneos como Savater (1991; 1997), Fromm (1947), Foucault (1984), Lipovetsky (1992) y otros. Es decir, hay una preocupación ética centrada en la persona, la vida, la toma de decisiones y los códigos del deber ser. La representación está con un paradigma presente en la literatura específica sobre la ética aunque muy amplio en su espectro ideológico.

\section{Educación en valores}

La segunda pregunta de aproximación fue la de tratar de relacionar la educación con los valores. Como en otras preguntas lo que nos interesaba era la opinión concreta de los participantes. Llama la atención que varios informantes asociaron la educación y los valores como un pleonasmo o redundancia:

En lo primero que pienso es en una frase hueca acuñada por los burócratas que no significa nada y que justifica cualquier actitud. Dejando de atrás a las hordas de la empleocracia política se me viene a mentes una redundancia, una perogrullada, "educar en valores" es lo mismo que decir "subir arriba". Si no hay valores no hay educación, hay ignorancia (inf. 4).

Incluso, además, relacionándola con la educación y la comunicación:

Redundancia. La educación es, en esencia, la comunicación de valores. Sin embargo, educación en valores me remite a que el docente, en su labor diaria, hace explícitos esos valores en los contenidos de sus clases (inf. 2).

Otros informantes, reconociendo esta reiteración, tratan de dar una explicación del por qué aparecen estos términos ligados pedagógicamente:

Un discurso emergente que busca redireccionar y redimensionar el significado de los valores y la forma e intención de remitirse a ellos (inf. 8).

Representación social y formas de aproximación didácticas $\bullet 265$

$y$ éticas al cine por maestros:

una exploración con palabras, creencias, estrategias e imágenes 
Más todavía, ven en esta irrupción una ventana de oportunidad:

Honestamente lo considero como una especie de pleonasmo. Es decir, todo acto educativo lleva valores implícitos, inherentes a la cultura e identidad de quien educa y es educado. Asimismo, considero que la expresión "educación en valores" proviene de otra: "es necesario rescatar los valores, porque se han ido perdiendo", y esta última me remite a la nostalgia de un pasado ideal (bipotético) de cierta cultura que no puedo dilucidar muy bien cuál es. Sin embargo y a pesar de todo lo anterior, considero que puede ser una oportunidad de reflexionar acerca de aquello que conforma la identidad personal y comunitaria en la que se vive y problematizar nuestra actuación en ella. (inf. 6).

Hay un segundo grupo de respuestas que resultan interesantes por que aluden al otro, en el deber ser. Se preocupan y distancian simultáneamente, como seńalando un destino casi siempre educativo, sin encontrarse implicados. Ejemplo de ello son las siguientes frases:

La idea o noción de que, sobre todo a los jóvenes por su condición, es posible enseñar una serie de normas o formas de actuar (inf. 5).

A la formación de personas con cierto nivel moral, es decir a formar personas con cierta sensibilidad hacia la persona (inf. 3).

La educación del ser humano mediante la sensibilización con cada uno de los valores que hacen sensible e inteligente para su crecimiento (inf.10).

\section{Las funciones del cine}

Otro indicador subjetivo para analizar en los consultados fueron las funciones del cine. Lo primero que encontramos es que la lista de lo que se le asigna al cine como función social es grande y diversa, mucho más de lo esperado en términos hipotéticos, sobre todo si no descartamos o unificamos las palabras que pueden resultar sinónimos, porque para el informante pudieran no resultar lo mismo (por ejemplo: entretener, recrear y distraer).

Sin embargo, cuando el término se emplea de manera idéntica, sí quedó agrupado. Presentamos la lista de las 33 palabras para las que sirve el cine según los informantes. 


\begin{tabular}{|l|l|l|}
\hline Evasión & Distraer (2) & Proyección de realidades y ficciones \\
Consuelo & Anunciar & Refleja vidas que no conocemos \\
Goce estético & Difusión & Denuncia injusticias (2) \\
Cambiar las narrativas & Propaganda & \\
Cultura (3) & Esparcimientiza (2) \\
Entretener (5) & Recreación & \\
Educar (7) & Expresión artística & \\
Crear arte & Documentación histórica & \\
Comunicar ideología & Convivencia & \\
Informar (3) & Expansión ideológica & \\
Aprender & Soñar & \\
Analizar & Pensar & \\
Motivar & Disfrutar & \\
Divertir & Reflexionar & \\
Provocar & & \\
\hline
\end{tabular}

De las palabras usadas por los informantes interpretamos varias cosas:

a) El listado de funciones (sociales, prácticas o absolutamente individuales) con que las que se vincula el cine resulta amplio, diverso y multirreferencial; según se observa en el listado, el cine es muchas cosas más que entretener y divertir con lo que comúnmente se le asocia;

b) Sin embargo, y tomando en cuenta la importancia que se le confiere actualmente al primer concepto (por ejemplo en estudios de posicionamiento) y porque metodológicamente así fue solicitado (Enumere en orden de importancia) tenemos que reconocer que dominan palabras como recreación, entretenimiento, diversión. La representación social del cine como evasión es todavía muy sólida;

c) Paradójicamente, la palabra más repetida es educación, con siete menciones (sin considerar palabras asociadas como: aprendizaje, cultura o información). Aunque, reconocemos un sesgo profesional en la muestra, e incluso del instrumento mismo, no deja de ser significativo que después de lo recreativo, lo educativo tenga relevancia;

d) Para un futuro dejamos la oportunidad de profundizar en algunos términos útiles, comunes o raros, con que se sirven los informantes del cine, como pueden ser soñar, provocar, documentación histórica, expansión ideológica, etcétera.

¿Educa el cine?

A pesar de que la representación social sobre la educación todavía está muy enmarcada en la lógica de la escuela, la acreditación y la certificación (Jaim Et-

\section{Representación social y formas de aproximación didácticas • 267 y éticas al cine por maestros:} una exploración con palabras, creencias, estrategias e imágenes 
cheverry 1999), sobre todo por las corrientes pedagógicas que dominaron hasta la primera mitad del siglo XX, las respuestas sobre si el cine educa resultaron casi unánimes, en el sentido afirmativo. Sólo hay una discrepancia señalando, con cierto enfado que la pregunta es manipuladora, comparándola con otras que consideraba semejantes:

Puede educar y puede llenarnos de ignorancia, la pregunta es manipuladora, es como decir: “el agua limpia?", y si, claro, puede limpiar, pero el agua estancada se llena de hongos y eso no es muy higiénico. El agua es agua como el cine es cine, su función dependerá de quién y cómo los utilice (inf. 4).

Tal vez por consecuencia de la arquitectura del instrumento, dada la pregunta anterior, al profundizar en el por qué el cine es factor educativo, lo que contestan casi siempre ampliando sobre las cuestiones: ¿En qué educa? ¿¿Sobre qué educa? lo que sin duda es una ganancia. De tal suerte que encontramos un universo mayor de aspectos, razones y argumentos del cine como educador.

Señalaremos sólo algunos rasgos detectados por los informantes de sobre que educa el cine: sobre mundos posibles, diversos referentes, comunica valores, formas de vida, de actuar, de pensar, presenta casos, aspiración, sentimientos, aprendizajes, decisiones, provee una lectura de la realidad, moldea la identidad, forma actitudes, es un medio de transferencia del conocimiento y comunica situaciones y acontecimientos.

\section{Los valores: ¿se aprenden o se enseñan?}

Esta es una cuestión central en la exploración para el desarrollo de la propuesta didáctica que pretendemos elaborar. Hay diferentes voces en la literatura educativa (Guevara, 2007) que expresan que no es fácil enseñar a otro ser humano los valores. Es decir, la caridad, la compasión, el amor, la pasión, el deber, la tolerancia, la responsabilidad, el compromiso, etc., son actitudes de la persona con cierto nivel de profundidad, vividos, internalizados y asumidos conscientemente. Lo que sostienen algunos pedagogos es que tiene que aprenderse con experiencias cercanas y, por lo que para que surta efecto, la enseñanza tiene que ser viva cognitiva y afectivamente, como proceso de apropiación (mayo, 2008).

Lo anterior no se puede aprender bajo un esquema tradicional de enseñanza, en el que alguien dicta y el otro memoriza y repite. Se interioriza por lo que vive y hace suyo la persona, por ejemplo, mediante experiencias, recomendaciones prácticas o emociones, por lo que el proceso educativo en valores debe tomar 
en cuenta todo lo anterior, y no enfrentarlo como un contenido más que se adereza al currículo.

En nuestra indagación apostábamos hipotéticamente a que las opiniones en este punto se polarizarían: una parte de los maestros consultados optaría por que los valores se pueden (deben) enseñar y otros opinarían que los valores se aprenden por la experiencia de la vida. Los datos fueron hacia otra parte. En la totalidad de los casos coincidieron en vincular la enseńanza con el aprendizaje. Leamos algunas verbalizaciones:

Los valores se aprenden a través de la experiencia de vida, pero se clarifican gracias a los discursos edificantes que diversas instituciones postulan (inf. 1).

Es un proceso dialéctico en que interactúan (inf.2).

Ambas. Naturalmente, nuestra formación tiene que ver desde el seno de la familia, por lo tanto muchas veces somos el reflejo de lo que vemos y vivimos en casa, los principios que nos conforman y los valores que nos integran como persona la mayor parte de los casos son enseñados por nuestros padres of familiares cercanos. (inf. 3).

Se aprenden y se enseñan, es un círculo, alguien los "enseña", es decir, los muestra, es decir, los ejerce (...) los "enseña" para que otro alguien los "aprenda" y asi sucesivamente. (inf.4).

(...) si los valores se enseñan, es necesario que se aprendan. (inf. 5).

La educación lleva implícitos los valores de los sujetos involucrados. A través del proceso educativo uno aprendelcomprende lo que tiene valor en su cultura y decide lo que tiene valor para si mismo (inf.6).

Se aprenden ya que se parte de un aprendizaje por imitación y por derivación de enseñanzas directas o indirectas. (inf. 7).

-Ambos casos. Primero se aprenden, al seno familiar y escolar (...) De ahi, va adquiriendo otros conceptos valorales y/o redimensionando otros a partir de otros medios como la experiencia, la lectura, el cine, (inf.8).

Se enseñan y se aprenden. Se enseñan de generación en generación tanto en la familia, en la escuela y dentro de grupos sociales. El aprendizaje de los valores se da en aquel individuo que tiene consciencia de la importancia de éstos y que, además, tiene la disposición y la actitud de que con el aprendizaje de los valores gana como ser humano (el subrayado también es del informante 9).

Los valores pueden aprenderse y enseñarse, ya que muchas veces hasta que una persona no se topa con una situación especifica no entiende el dilema que puede presentarse por la omisión o la decisión de potenciar un valor (inf. 10).

Como se observa, es notable, y en algunos casos con un buen fundamento teórico de diversos cuerpos conceptuales, la manera en que los informantes

Representación social y formas de aproximación didácticas $\bullet 269$

$y$ éticas al cine por maestros:

una exploración con palabras, creencias, estrategias e imágenes 
integran y asocian la enseñanza con el aprendizaje como forma de respuesta que evade la disyuntiva; sin embargo, la experiencia pedagógica nos hace inferir que no siempre en la realidad educativa la relación enseñanza-aprendizaje es tan natural o mecánica. Lo que se enseña no necesariamente es lo que se aprende y viceversa. Lo que vemos como significativo en la muestra es que a pesar de la solvencia teórica plasmada en categorías y conceptos predomina una representación social causal, mecánica y tradicional del hecho educativo.

\section{Películas de cualquier tiempo y lugar y los valores que se decantan de ellas}

Ya más próximos al cine y la ética, en la siguiente pregunta nos interesaban principalmente dos aspectos:

1) Saber el fondo cultural y ético con que contaban los entrevistados y como relacionaban las películas con los valores.

2) También si había recordación de la escena con el valor. Esto sobre todo porque es algo que ya teníamos pensado como estrategia y queríamos saber qué pensaban y cuál era su reacción en el momento de aportar.

Los informantes compartieron, en total, 47 películas. La mayoría de las últimas tres décadas (1970-2000), notando que menos de cinco son del último lustro. Creemos que se espera la prueba del tiempo para que una película pueda ser recomendada en el sentido que se los solicitábamos, aunque hay evidentes contra ejemplos: Juno y El laberinto del fauno, que al parecer ya no lo necesitaron.

Los filmes que arroja la muestra son dominantemente estadounidenses, lo que era predecible, como lo manifestábamos a nivel hipotético, por la hegemonía de esta nación (baste analizar la cartelera cinematográfica de cualquier país en los últimos 50 años), sin embargo, y a pesar de ello, hay también productos de otras cinematografías y bastante bien representadas, como la mexicana, española, italiana, inglesa, australiana y japonesas. Hay películas clásicas, consideradas así por los expertos (Mamet, 1991; Gubern, 2000), de la mayoría de los géneros (intimistas, bélicas, costumbristas, musicales, históricas, infantiles, melodramas, fantásticas, thrillers, westerns), ubicadas en corrientes como el neo-realismo, Dogma o la nueva ola francesa, o cine de autor como Kurosawa, Kubrick o Kieslowski. La lista en sí misma es de un inmenso valor.

Con relación a los principios y valores encontramos variedad y, en general, el valor que señalan está bien integrado en la película. Los valores más referidos, con más de tres menciones, son la libertad, el amor, el respeto, la constancia y la amistad.

270 - Rafael Tonatiuh Ramírez Beltrán 
Aunque no nos detendremos en las posibles interpretaciones de las razones por las que esos valores se mencionaron, incluimos, por la importancia que puede tener para los procesos educativos, la lista y cuadro completo que resume esta pregunta.

\begin{tabular}{|l|l|l|}
\hline PELículas & VALORES & EsCENA \\
\hline 1. Amelie & Ayuda & $\begin{array}{l}\text { Amelie decide concretar historias trágicas, } \\
\text { incompletas, tristes, etc. de una forma alegre, } \\
\text { buscando siempre el final feliz adecuado para } \\
\text { cada una de ellas, lo más importante sin lograr el } \\
\text { reconocimiento público. }\end{array}$ \\
\hline $\begin{array}{l}\text { 2. Perfume de } \\
\text { mujer }\end{array}$ & Vida & $\begin{array}{l}\text { Cuando Charlie se niega a salir del cuarto donde el } \\
\text { coronel Frank está a punto de quitarse la vida. }\end{array}$ \\
\hline $\begin{array}{l}\text { 3. El laberinto del } \\
\text { fauno (inf.3, inf.1) }\end{array}$ & $\begin{array}{l}\text { Constancia, el } \\
\text { valor de la libertad } \\
\text { y la dignidad de la } \\
\text { persona humana. }\end{array}$ & $\begin{array}{l}\text { Cuando Ofelia supera pacientemente una a una } \\
\text { todas las pruebas para lograr regresar a gobernar } \\
\text { junto a sus padres el reino prometido por el fauno. }\end{array}$ \\
\hline $\begin{array}{l}\text { 4. Across the } \\
\text { universe }\end{array}$ & Amor & Toda la película. \\
\hline 5. Big Fish & $\begin{array}{l}\text { Amistad y } \\
\text { perseverancia }\end{array}$ & Toda la película. \\
\hline $\begin{array}{l}\text { 6. La misión } \\
\text { La responsabilidad } \\
\text { histórica y la } \\
\text { dignidad de la } \\
\text { persona }\end{array}$ & $\begin{array}{l}\text { Tanto en el juicio sobre la humanidad de los } \\
\text { indígenas como en la escena final. }\end{array}$ \\
\hline $\begin{array}{l}\text { 7. Hasta morir } \\
\text { (inf.1, inf.2) }\end{array}$ & $\begin{array}{l}\text { La amistad, } \\
\text { Identidad }\end{array}$ & $\begin{array}{l}\text { Cuando se enfrentan los cholos tras el alejamiento. } \\
\text { El personaje del chavo banda, Urbano, se manda } \\
\text { a hacer un tatuaje. Cuando se lo ponen, le duele } \\
\text { tanto que llega hasta las lágrimas. El personaje del } \\
\text { Cholo le explica que un tatuaje no es una moda ni } \\
\text { una tontería, que "un tatuaje se gana". }\end{array}$ \\
\hline $\begin{array}{l}\text { 8. El señor de los } \\
\text { anillos }\end{array}$ & Humildad & $\begin{array}{l}\text { Cuando Galadriel renuncia al uso del Anillo de } \\
\text { Poder. }\end{array}$ \\
\hline $\begin{array}{l}\text { 9. La sociedad de } \\
\text { los poetas muertos }\end{array}$ & Libertad & Las clases del profesor Keating. \\
\hline $\begin{array}{l}\text { 10. Cinema } \\
\text { Paradiso }\end{array}$ & Amor/fidelidad & La fábula contada por Alfredo a Toto. \\
\hline 11. Billy Elliot & $\begin{array}{l}\text { Constancia/ } \\
\text { Esfuerzo }\end{array}$ & Toda la película. \\
\hline 12. Amistad & Igualdad & $\begin{array}{l}\text { El momento en que los esclavos observan } \\
\text { ilustraciones (de Doré) un una Biblia y las } \\
\text { interpretan haciendo una analogía del sufrimiento } \\
\text { de Cristo con el de ellos mismos. }\end{array}$ \\
\hline
\end{tabular}

\section{Representación social y formas de aproximación didácticas $\bullet 27 \mathrm{I}$ $y$ éticas al cine por maestros:}

una exploración con palabras, creencias, estrategias e imágenes 


\begin{tabular}{|c|c|c|}
\hline $\begin{array}{l}\text { 13. Ben Hur } \\
\text { (inf.4, inf.7) }\end{array}$ & $\begin{array}{l}\text { Orgulloso, } \\
\text { amistad y } \\
\text { congruencia. }\end{array}$ & Ben Hur en las galeras \\
\hline $\begin{array}{l}\text { 14. Lo que el } \\
\text { viento se llevó }\end{array}$ & Coraje & Juro por la tierra roja de Tara... \\
\hline $\begin{array}{l}\text { 15. La lengua de } \\
\text { las mariposas }\end{array}$ & Entrega & El maestro enseñándole al niño. \\
\hline 16. Beau Geste & Hermandad & Luchando juntos hasta la muerte. \\
\hline $\begin{array}{l}\text { 17. El puente sobre } \\
\text { el rio Kwai }\end{array}$ & Dignidad & Soldados ingleses silbando. \\
\hline 18. Gallipoli & Pacifismo & $\begin{array}{l}\text { Los soldados saben que van a morir, que es } \\
\text { absurdo y sin sentido, pero cumplen órdenes. El } \\
\text { sargento mayor deja su anillo de boda clavado en la } \\
\text { trinchera y el protagonista se despoja de sus armas } \\
\text { para una última carrera a la muerte. }\end{array}$ \\
\hline 19. El pianista & Responsabilidad & $\begin{array}{l}\text { Uno no sólo es víctima de la vida, sino que } \\
\text { es responsable por la toma de sus decisiones. } \\
\text { Szpillman no acepta entrar a la policía aunque eso } \\
\text { pueda traerle la muerte. }\end{array}$ \\
\hline 20. Mente brillante & Sacrificio & $\begin{array}{l}\text { ¿De qué sirve todo el conocimiento si no amas? } \\
\text { John Nash dispuesto a sufrir el coma diabético } \\
\text { inducido por los psiquiatras en un intento por } \\
\text { curarlo con tal de poder vivir con su familia. }\end{array}$ \\
\hline 21. El perro & Paciencia & $\begin{array}{l}\text { "Coco" Villegas entiende que, a veces, las cosas } \\
\text { llegan casi por si solas, que es más cuestión de } \\
\text { no forzarlas, cuando encuentra a Bombón feliz } \\
\text { de la vida, con una perrita criolla, luego de haber } \\
\text { despreciado varias perras finas. }\end{array}$ \\
\hline $\begin{array}{l}\text { 22. Tres colores: } \\
\text { Azul (inf.6) }\end{array}$ & $\begin{array}{l}\text { Comprensión y } \\
\text { generosidad. }\end{array}$ & $\begin{array}{l}\text { La esposa regala su casa a la amante de su esposo } \\
\text { muerto. }\end{array}$ \\
\hline $\begin{array}{l}\text { 23. Ojos bien } \\
\text { cerrados }\end{array}$ & $\begin{array}{l}\text { La relatividad } \\
\text { de los actos } \\
\text { y "valores" } \\
\text { humanos. }\end{array}$ & El diálogo final. \\
\hline 24. Juana de Arco & $\begin{array}{l}\text { Fe, verdad, } \\
\text { humildad. }\end{array}$ & El diálogo entre Dios y la protagonista. \\
\hline 25. Blade Runner & $\begin{array}{l}\text { Amor como } \\
\text { entrega de la vida }\end{array}$ & Final \\
\hline $\begin{array}{l}\text { 26. Buscando a } \\
\text { Nemo }\end{array}$ & $\begin{array}{l}\text { Comunicación, } \\
\text { convivencia }\end{array}$ & Toda la película \\
\hline 27. Días sin huella & Compromiso & Toda le película \\
\hline $\begin{array}{l}\text { 28. Rocco y sus } \\
\text { hermanos }\end{array}$ & $\begin{array}{l}\text { Amistad y } \\
\text { congruencia. }\end{array}$ & Toda la película \\
\hline
\end{tabular}




\begin{tabular}{|c|c|c|}
\hline $\begin{array}{l}\text { 29. La fuerza de } \\
\text { uno }\end{array}$ & Disciplina & Toda la película \\
\hline 30. Canoa & Tolerancia & Toda la película \\
\hline $\begin{array}{l}\text { 31. Los siete } \\
\text { samuráis }\end{array}$ & Cooperación & La escena de la batalla \\
\hline 32. El padrino & $\begin{array}{l}\text { Lealtad, } \\
\text { honorabilidad, } \\
\text { amor }\end{array}$ & Al Pacino diciendo: La familia es la familia. \\
\hline 33. Tres Colores & $\begin{array}{l}\text { Igualdad, } \\
\text { fraternidad, } \\
\text { libertad }\end{array}$ & $\begin{array}{l}\text { Igualdad: Blanco } \\
\text { Libertad: Azul } \\
\text { Fraternidad: Rojo }\end{array}$ \\
\hline 34. El violin & $\begin{array}{l}\text { Libertad, } \\
\text { participación, } \\
\text { respeto. }\end{array}$ & Participación y liderazgo de guerrilleras. \\
\hline 35. Mar profundo & Amor & En la ayuda que pide el enfermo. \\
\hline 36. Trainspotting & $\begin{array}{l}\text { Fraternidad, amor } \\
\text { y compromiso. }\end{array}$ & $\begin{array}{l}\text { Renton (personaje principal) le deja dinero a su } \\
\text { amigo en caja de seguridad. -Los padres, por culpa, } \\
\text { ayudan a la desintoxicación. }\end{array}$ \\
\hline 37. Juno & $\begin{array}{l}\text { Respeto, } \\
\text { solidaridad }\end{array}$ & Madrastra y papá ayudando a Juno. \\
\hline 38. El odio & $\begin{array}{l}\text { Libertad, } \\
\text { tolerancia }\end{array}$ & Toda la película \\
\hline 39. Yo soy Sam & $\begin{array}{l}\text { Amor filial y } \\
\text { respeto }\end{array}$ & Toda la película \\
\hline 40. Billy Elliot & $\begin{array}{l}\text { Tolerancia y } \\
\text { respeto }\end{array}$ & Toda la película \\
\hline 41. Ali & Libertad & $\begin{array}{l}\text { Alí levanta su voz en contra del gobierno } \\
\text { estadounidense en tiempos de la guerra en } \\
\text { Vietnam. Decide no ir a la guerra pues "esa gente } \\
\text { no lo ha maltratado, no tiene nada en contra de } \\
\text { ellos y, al contrario, el blanco estadounidense no } \\
\text { ha hecho más que maltratarlo a él y a su raza". } \\
\text { Increíble la valentía de un solo hombre contra todo } \\
\text { un sistema de gobierno del país más poderoso del } \\
\text { mundo. }\end{array}$ \\
\hline 42. Gandhi & Paz & $\begin{array}{l}\text { Durante prácticamente toda la película. Como en } \\
\text { la anterior película, vemos cómo una sola persona } \\
\text { frente al mundo da prueba del valor de la paz sin } \\
\text { violencia. "Ojo por ojo y todos estaríamos ciegos" }\end{array}$ \\
\hline $\begin{array}{l}\text { 43. Peliculas del } \\
\text { Holocausto }\end{array}$ & $\begin{array}{l}\text { Respeto por sí } \\
\text { mismos }\end{array}$ & $\begin{array}{l}\text { En las innumerables películas que denuncian los } \\
\text { horrores del holocausto podemos tomar como } \\
\text { ejemplo grandes muestras de valor personal por } \\
\text { defender las injusticias vividas, que dan como } \\
\text { resultado, pruebas de respeto por sí mismo. }\end{array}$ \\
\hline
\end{tabular}

\section{Representación social y formas de aproximación didácticas $\bullet 273$ y éticas al cine por maestros:}

una exploración con palabras, creencias, estrategias e imágenes 


\begin{tabular}{|l|l|l|}
\hline $\begin{array}{l}\text { 44. Los hombres de } \\
\text { mi vida }\end{array}$ & Responsabilidad & $\begin{array}{l}\text { Durante toda la película podemos darnos cuenta } \\
\text { que, a pesar de que una mujer puede ser madre a } \\
\text { muy temprana edad, la responsabilidad por cuidar } \\
\text { y sacar a su hijo adelante no es cuestión de edad } \\
\text { sino de actitud y valentía. }\end{array}$ \\
\hline $\begin{array}{l}\text { 45. Rabbit-Proof } \\
\text { Fence }\end{array}$ & Amor & $\begin{array}{l}\text { El amor demostrado hacia las familias étnicas } \\
\text { cuando el gobierno realiza operaciones de "limpieza } \\
\text { étnica". Dos niñas hacen todo por regresar al lado } \\
\text { de su madre y su abuela. }\end{array}$ \\
\hline 46. Eight Below & $\begin{array}{l}\text { Amor hacia los } \\
\text { animales, Lealtad. }\end{array}$ & $\begin{array}{l}\text { En la película vemos reflejado el profundo amor } \\
\text { que las personas pueden llegar a sentir por los } \\
\text { animales. También vemos la impresionante lealtad } \\
\text { que un perro puede llegar a tener hacia su amo, } \\
\text { digno de que los humanos lo imitemos. } \\
\text { (perdón pero me acordé ahorita de ésta y se me } \\
\text { hizo importante hablar de valores distintos en } \\
\text { donde están presentes los perros) }\end{array}$ \\
\hline 47. Magnolia & El perdón & $\begin{array}{l}\text { El papel que representa Tom Cruise, haciendo las } \\
\text { paces con su padre al borde de la muerte }\end{array}$ \\
\hline 48. Sueño de fuga & Perseverancia & $\begin{array}{l}\text { El papel que representa Tim Robbins tardó durante } \\
\text { 20 años en toda la película en hacer un túnel hacia } \\
\text { su libertad. }\end{array}$ \\
\hline
\end{tabular}

\section{Cine actual}

En la pregunta a los informantes se les propuso un primer recorte de peliculas recientes que habiamos detectado se podrian trabajar en términos de valores.

De las quince películas, la más referida fue el Laberinto del fauno. Supusimos que se debía al éxito que tuvo primero en Europa (Cannes/Francia y en los Goyas/ Espańa) y luego en nuestro país después de la llamada "noche mexicana" en la premiación del Óscar de febrero de 2007.

Además de este palmarés, es innegable el nivel de calidad cinematográfica que tiene la película.

Algunas frases que mencionan sobre El laberinto del fauno con relación a los valores son las siguientes:

La película está repleta de enseñanzas. Particularmente, la parte de la libertad creativa de la niña, cuando tiene que construir su historia paralela frente a la tirania (inf. 1).

Me parece que toda la cinta resalta la inocencia infantil como forma de sobrevivencia en un mundo desgastado y dividido por la guerra (inf. 2).

La solidaridad se ve en la escena en que la actriz Maribel Verdú y el doctor ayudan al hermano (inf. 8). 
La valentía y el amor hará luchar por su familia para luchar en contra del tirano (inf. 9).

Como se puede observar, son varios los valores que se pueden rescatar de la película mayormente nombrada entre los informantes, pero cabe destacar en esta pregunta que notamos que la mayoría de las películas propuestas a ellos en el primer listado no habían sido vistas. Suponemos que esto se debe a que se proyectaron en los circuitos culturales de la ciudad de México (casas de arte, festivales, Cineteca Nacional, cartelera universitaria, muestras) y por muy poco tiempo; a veces una sola función o semana, hecho que bien visto resulta absurdo en una de las ciudades más grandes del planeta. Esto se puede corregir, como está sucediendo, al aparecer esas películas en otros formatos (DVD) y puedan ser vistas y usadas por los colectivos escolares.

\subsection{OtRAS RECOMENDACIONES DE PELÍ́CULAS CONTEMPORÁNEAS}

En esta pregunta, lo que tratábamos de entender, en correlato a la pregunta anterior, era que los informantes nos sugirieran películas actuales susceptibles de ser trabajadas con valores y que no estuvieran en la lista que proponemos. La delimitación, como se sabe, era el último lustro: 2003-2008. En efecto, aquí también buscábamos contrastar nuestras creencias.

La lista arrojó productos cinematográficos interesantes, por lo que decidimos incorporar algunas a la parte final del texto de las estrategias didácticas y recomendar todas. Esta es una nueva lista del cine del último lustro que se puede manejar éticamente en el salón de clases y que se desprende de los informantes. También la compartimos a continuación porque da también pistas de trabajo. Se anotan como fueron expresadas y no técnicamente.

- Dogville

- Los niños del fin del mundo

- Across the Universe

- Big Fish

- Los falsificadores

- Qué hacer en caso de incendio

- Asesino al asecho

- Escritores por la libertad

- Erin Brokowich

- Antes de partir

Representación social y formas de aproximación didácticas $\bullet 275$ $y$ éticas al cine por maestros: una exploración con palabras, creencias, estrategias e imágenes 
- Farenhtheit 911

- Sin lugar para los débiles

- Petróleo sangriento

Del mismo modo, tomamos la decisión de incluir algunas de estas películas como recomendaciones complementarias específicas de algunas películas con temas cercanos.

Estrategias didácticas y cine

Dado el perfil del informante que buscamos (profesionales de la educación), las respuestas aquí también tienen un incalculable valor, por lo que al igual que en otras preguntas, titulamos y sintetizamos algunas de las estrategias didácticas que recomendaron los informantes:

1. De la sorpresa a la actividad:

Enfrentar al alumno a la sorpresa de la proyección y generar una discusión guiada tras la película, o bien, generar una guía de tópicos a observar en la película (se recomienda como actividad didáctica). Puede ser un cartel para la misma o un spot publicitario que articule lo estudiado (inf.1).

2. El valor universal:

Plantear un valor humano, universal o cultural, explicándolo, para después llevar a cabo la proyección (inf.2).

3. Relacionar con otro medio:

Enriquecerlos con series como los Simpson o Malcom el de en medio que en el fondo transmiten ciertas cuestiones éticas (inf. 3).

4. Proximidad, giro y explicación:

Lo esencial es que sean películas que "peguen" en la juventud. Esa creo que es una estrategia básica y se remonta al mismo momento de elegir la película, los alumnos se maravillan cuando de peliculas (o canciones o revistas o productos) que ellos consumen a diario el maestro puede extraer análisis que le dan otra vuelta a la tuerca (...) la tarea del profesor es desmenuzar las películas y mostrar (o mejor, hacer que los alumnos encuentren) los valores que muestran (inf. 4).

5. El camino de la toma de decisiones:

1. Comentar antes de la clase situaciones referentes a la claudicación de los ideales con el paso del tiempo.

276 - Rafael Tonatiuh Ramírez Beltrán 
2. Debate que deberá quedar abierto acerca del tema.

3. Después de la película, los alumnos tratarán de explicar qué llevó a cada uno de los personajes a tomar sus decisiones, qué consecuencias tuvieron (en lo individualy en lo social).

4. Los alumnos valorarán esa toma de decisiones.

5. Se puntualiza a lo largo de toda la clase que de lo que se trata es, precisamente, de la importancia de tomar decisiones y asumir sus consecuencias (inf. 5).

6. Los pasos de entender al cine como dilema ético:

1. Establecimiento de un dilema ético relacionado con el contenido de la clase y en relación con los destinatarios.

2. Propuestas de lo que se haría en ese caso.

3. Presentación de escenas de peliculas donde aparezca ese dilema o uno parecido (contextualizado).

4. Discusión acerca de cómo se resuelve en cada caso.

5. No perder de vista que no se trata de defender un valor o valores a ultranza, sino de comprender la situación (inf. 6).

7. Actitudes y valores de los protagonistas:

1. Que los alumnos identifiquen en los protagonistas valores especificos y cómo son desarrollados por estos.

2. Que los alumnos puedan analizar y generalizar las actitudes y conductas de los protagonistas hacia nuevas situaciones y problemas cotidianos (inf. 7).

8. Dinámicas grupales:

- Diálogo simultáneo (cuchicheo)

- Técnica expositiva

- Método de caso

- Dramatización

- Debate dirigido

- Lluvia de ideas

\section{Discusión}

Para poder establecer el valor de lo que encontramos en las respuestas de nuestros informantes, partimos de lo que señala y concentra Garzón Bates (1997) con respecto a la ética y su sentido:

La ética se ocupa de nuestro comportamiento dentro de la sociedad, pero a diferencia de la moral, no prescribe el curso de nuestra conducta o nuestras acciones incluso establecen

Representación social y formas de aproximación didácticas $\bullet 277$ y éticas al cine por maestros: una exploración con palabras, creencias, estrategias e imágenes 
bases para criticarla. De alli que abra la posibilidad de comportamientos distintos de los de la moral establecida por una comunidad o por la sociedad. La ética puede ayudarnos a elegir, pero no nos impone rígidamente una elección.

Justamente lo que nos parece más revelador de la investigación exploratoria es la facultad personal que ejercen los maestros, como actores principales del hecho educativo, de asumir sus saberes y creencias y ponerlos en juego para que respondan creativamente ante el desafío formativo de los alumnos.

Lo que resulta evidente es que el formar éticamente aún con un medio como el cine que proponemos, en sí mismo es complejo, se reestructura didácticamente de muy diversas maneras por los maestros. En los datos notamos más que prescripción didáctica propuestas innovadoras para el salón de clase, de un conocimiento del que se fueron apropiando los profesores a lo largo de su vida, en experiencia y muy seguramente lecturas y pláticas informales en las que especulamos por la calidad y contundencia de las respuestas en cuanto a un saber escolarizado, más allá de donde fueron formados académicamente. Pero que además en forma solvente utilizan (o por lo menos sabrían como utilizar, por lo que reportan) en su quehacer cotidiano educativo.

\section{Conclusiones}

1. Para el colectivo de informantes consultados las tres categorías que se desprenden del término ética y que son centrales a esta investigación son: En primer lugar, la ética y su estrecha relación con la vida de las personas; con los comportamientos, con la conducta, con las acciones de todos los días.

La segunda categoría es la de toma de decisiones y es la que sin duda nos abrió una inmensa ventana sobre lo que creemos debe trabajarse en la relación cine y ética. Nos explicamos; en las películas, los protagonistas de las historias lo que hacen inevitablemente es tomar decisiones que dan continuidad o giros a los acontecimientos. De ahí la luz que tomó este dato. Lo que propondremos en el trabajo de las películas gracias a este hallazgo es marcar muy claramente las secuencias y proponerles preguntas que insistentemente hagan a los alumnos observar y seguir las decisiones que van tomando los involucrados en las tramas, lo que permitirá que la observación de las películas se haga de forma alterna y minuciosa.

La tercera categoría es tal vez a la que más se recurre cuando se alude al concepto de ética (valores, principios, normas etcétera). Lo que inferimos

278 - Rafael Tonatiuh Ramírez Beltrán 
finalmente es que no estamos ante un concepto el cual se puede explicar de una vez y para siempre. La ética es una disciplina que se puede manejar de distintas aristas.

2. Una segunda gran enseñanza que se desprende de esta investigación es la clara asociación que hay entre educar y educar en valores, prácticamente la información que obtuvimos no ve forma de desprender la educación de la ética. Pero sería muy interesante contrastar este punto de vista que arroja la información con la realidad escolar sobre todo en dos cosas:

a. Que este proceso no siempre se da en los espacios escolares. Lamentablemente, todavía los maestros imparten la clase que les toca cumpliendo con el programa en el cual no hay espacio temporal para un trabajo formativo integral del educando.

b. La incorporación que se ha hecho de la ética, la educación en valores o el civismo, así como los espacios de formación y humanismo, son casi siempre propuestas duras, rígidas y que aparecen casi siempre de manera curricular como materias; los maestros y los alumnos las asumen como las otras asignaturas que hay que tomar o impartir y acreditar o evaluar. Tampoco aquí hay mayor trabajo formativo y sólo exponer y muchas veces memorizar los contenidos.

3. Los lugares comunes en que el cine sólo divierte y entretiene volvieron a aparecer en las representaciones que tenían los informantes sobre el cine. Sin embargo, hay dos datos muy reveladores en la información: el cine sirve para muchas cosas más que para evadirse y el cine se ha incrustado de forma irreversible en los procesos educativos de aprendizaje y culturales. Es muy claro que esto, se puede constatar cada vez más en casi cualquier centro escolar; los maestros utilizan el cine para promover aprendizaje.

4. Existe consenso según la información obtenida de que el cine educa y se muestra evidencia de que el cine educa de muy diversas maneras y sobre lo más distintos objetos de conocimiento y contenidos. Recomendamos para una investigación etnográfica lo que queda por saber, por ejemplo, los logros completos alcanzados en la utilización del medio con fines educativos.

5. Los valores se enseñan y se aprenden concluyen los informantes casi sin encontrar ruptura entre ambos. Sin embargo nosotros insistimos en que muchas

Representación social y formas de aproximación didácticas 279 $y$ éticas al cine por maestros: una exploración con palabras, creencias, estrategias e imágenes 
veces sobretodo en la realidad actual lo que dice/enseña el maestro no es necesariamente lo que aprende el alumno. Y también de manera obsesiva pensamos que una mediación necesaria entre el mundo del aprendizaje y el mundo de la enseñanza pueden ser los medios trabajados de otra manera.

6. El valor supremo que tiene como hallazgo la presente investigación es, a nuestro juicio, poder mostrar el capital intelectual y de representación (conceptos, películas, estrategias, usos) del que disponen los maestros, más allá de lo que específicamente dan como clase, la materia que imparten o su formación. Ninguno de ellos es maestro de ética o cine; sin embargo, en sus opiniones la solvencia y entereza sobre el tema de consulta es muy evidente. La recomendación aquí es muy puntual: profundizar y ampliar esta investigación a otros colectivos docentes, incorporando siempre, como más adelante lo intentaremos, su conocimiento, sabiduría, desprendimiento y generosidad.

7. En la literatura de las Ciencias Sociales en general y en la de la Ciencia de la Comunicación y Educación, en particular, es muy socorrido el argumento (por ejemplo en los textos didácticos) de la importancia y el carácter insustituible del profesor. Pero como en todos los lugares comunes lo relevante es demostrar que en efecto los maestros son distintos y tienen estrategias distintas. Este trabajo muestra como comprenden y usan el medio cinematográfico una muestra de profesores en forma creativa e innovadora.

El uso del cine en el aula escolar, que venía gestándose desde la tecnología educativa -implementada en América Latina desde los setenta del siglo pasadoalcanzó su derecho pedagógico y generalización tecnológica (por lo menos en los centros escolares urbanos promedio) en la primera década del siglo XXI. Sin embargo, es indispensable no saltarse el rito de iniciación que significa repensar el medio en ámbitos educativos.

Por lo anterior, lo que nos proponemos como trabajo inmediato es retomar los datos aquí expuestos para el diseño de una estrategia general didáctica para el trabajo de los films que incluyan elementos como: la novedad, la ficha técnica, el trabajo con fotogramas, escenas, secuencias, preguntas detonantes de ideas, trabajo previo, durante la proyección, reflexiones finales, dilemas éticos, etc. Por último, como resulta lógico nunca quisiéramos jamás sustituir al profesor, más bien estar juntos con él en la butaca o en el mesa-banco, aprendiendo a reutilizar al cine.

280 - Rafael Tonatiuh Ramírez Beltrán 


\section{REFERENCIAS}

Acosta, V.W. (2000). Las ciencias sociales a través del cine. Aula Abierta. Magisterio, Santa Fe de Bogotá, Sociedad Cooperativa Taller Abierto.

Agejas, J.A. (2007). La tarea de ser mejor. Curso de ética. Madrid: Universidad Francisco de Vitoria.

Aparici, R. \& García Matilla, A. (1987). Imagen, video y educación. Prólogo de Javier Arévalo Zamudio y Gerardo Ojeda Castañeda. México: Fondo de Cultura Económica.

Aristóteles (323 a.c.). Ética Nicomaquea. México: Ediciones Nuevo Talento.

Armendáriz, M. (2002). El juego de la fascinación. En La memoria de los sentidos. Basilio Martín y su obra audiovisual. 47o Semana Internacional de Cine. Valladolid España. Sociedad General de Autores y Editores. pp. 9-12.

Attali, J. (2007). Diccionario del siglo XXI. Barcelona: Paidós.

Augé, M. (1999). Antropologías de la sobremodernidad. En Estudios sobre las Culturas Contemporáneas, junio, año/vol. iI. Barcelona, España.

Benedicto XVI (2008). Los medios en la encrucijada entre protagonismo y servicio. Mensaje de su santidad Benedicto XV para la XLII Jornada mundial de las comunicaciones sociales. Roma, Italia: Libreria Editrice Vaticano.

Bollant, F. (2004). Michel Foucault y las prisiones. Buenos Aires: Ediciones Nueva Visión. Claves Perfiles, p. 11.

Blanco, J. (2007). Al Gore y el calentamiento global. En La Jornada 31 de julio de 2007. México.

Camareno, G. (2002). (ed.) La mirada que habla (cine e ideologia). Madrid: Akal/ Comunicación.

Chama, L. (2005). Complejizar el aula. En Complejidady transdisciplina: acercamientos $y$ desafios. México: Editorial Torres Asociados. pp. 109 - 122.

Contreras, S. (2002). La ética en la vida profesional. México: Editorial Trillas/ Universidad Anáhuac.

Debray, R. (1992). Vida y muerte de la imagen. Barcelona: Paidós.

Dietrich, H. et al. (2000). El fin del capitalismo global. El nuevo proyecto histórico. México: Océano.

Foucault, M. (1984). Historia de la sexualidad 2- El uso de los placeres. México: Siglo Xxi. pp. 26-29.

Fromm, E. (1947). Ética y psicoanálisis. México-Buenos Aires: Fondo de Cultura Económico. Breviarios No. 74.

Fullat, O. (1997). La peregrinación del mal. España: Planeta.

García, A. L. (1991). El testamento de Emma Godoy. México: Jus.

Garzón Bates, M. (1997). La Ética. Consejo Nacional para la Cultura y las Artes. Colección Tercer milenio. pp. $4-5$.

Guevara Niebla, G. (2007). Entrevista para el suplemento Campus, periódico Milenio 13 de septiembre de 2007. México.

Representación social y formas de aproximación didácticas $\bullet 28 \mathrm{I}$

y éticas al cine por maestros:

una exploración con palabras, creencias, estrategias e imágenes 
Gubert, R. (2000). Historia del cine. España: Lumen.

Gutiérrez, S. R. (1981). Introducción a la Ética. México: Esfinge.

Jaim Etcheverry, G. (1999). La Tragedia Educativa, México: Fondo de Cultura Económica.

Jarvie, I. C. (1978). El cine como critica social. México: Ediciones Prisma.

Kraus, A. (2008). Memorial de deudas. En la Jornada 16 de Abril del 2006 Sección Editorial. México. p. 18.

Lipovetsky, G. (1992). El crepúsculo del deber. España: Anagrama.

Mamet, D. (1991). Dirigir cine. México: Ediciones el Milagro/ imcine. Primera edición 1997. p. 28.

Mayo, I. (2008). Emoción, experiencia y educación, una mirada diferente. Ministerio de Ciencia, Tecnología y Medio Ambiente de Cuba. Ponencia presentada al V Encuentro Nacional de Investigación Educativa. Conie. Tepic. Nayarit.

Meixueiro, A. \& Ramírez, T, coord. (1998). La vida es mejor que la escuela. México: Sociedad Cooperativa Taller Abierto.

Meixueiro, A. \& Ramírez, T. (2000). Maestra vida. Sociedad Cooperativa Taller Abierto. México: Centro de Estudios superiores en Educación. Universidad Pedagógica Nacional.

Meixueiro, A. \& Ramírez, T. (2003). Globalización, cine y educación. Sociedad Cooperativa Taller Abierto. México.

Narro, J. (2008) “La tecnología rebasa el humanismo” en periódico Milenio Jueves 19 de junio de 2008, p. 45.

Sánchez de Armas, M.A. (2008). ¡Qué tiempos aquellos, señor Don Simón! En la sección Juego de Ojos, de Revista Virtual upaep. Puebla, México.

Savater, F. (1991) Ética para Amador. México: Planeta.

Savater, F. (1997). El valor de educar. México: Instituto de Estudios educativos y sindicales de América.

Subirats, E. (2008). Realidades artificiales y mentiras globales. Entrevista realizada por Juan Manuel García, en La Jornada Semanal Domingo 25 de mayo de 2008. No. 690. pp. 4-5.

Scheler, M. (1916). El formalismo en la ética y la ética material de los valores. Citado por Manuel García Morente. Obras Completas II Madrid: Edición Juan Miguel Palacios. pp.. 315-320.

Tejeda, A. (2008). El dominio enloquece al mundo: entrevista con Eduardo Galeano. En La Jornada. México. 30 de mayo de 2008. p. 52.

Uroz, J. (1999). Historia y cine. España: Publicaciones de la Universidad de Alicante. p. 225. Recuperado de: www.uhu.es/cine.educacion/cineyeducacion/

282 - Rafael Tonatiuh Ramirez Beltrán 